\title{
Using Vertically Integrated Projects to embed research-based education for sustainable development in undergraduate curricula
}

Development in undergraduate curricula

Scott Munro Strachan, Stephen Marshall and Paul Murray Department of Electronic and Electrical Engineering, University of Strathclyde, Glasgow, UK, and

\author{
Edward J. Coyle and Julia Sonnenberg-Klein \\ Georgia Institute of Technology, Atlanta, Georgia, USA
}

\begin{abstract}
Purpose - This paper aims to share the University of Strathclyde's experience of embedding research-based education for sustainable development (RBESD) within its undergraduate curricula through the use of an innovative pedagogy called Vertically Integrated Projects (VIP), originated at Georgia Institute of Technology.

Design/methodology/approach - This paper discusses how aligning VIP with the SDG framework presents a powerful means of combining both research-based education (RBE) and education for sustainable development (ESD), and in effect embedding RBESD in undergraduate curricula.

Findings - The paper reports on the University of Strathclyde's practice and experience of establishing their VIP for Sustainable Development programme and presents a reflective account of the challenges faced in the programme implementation and those envisaged as the programme scales up across a higher education institution (HEI).

Research limitations/implications - The paper is a reflective account of the specific challenges encountered at Strathclyde to date after a successful pilot, which was limited in its scale. While it is anticipated these challenges may resonate with other HEIs, there will also be some bespoke challenges that may not be discussed here.

Practical implications - This paper offers a practical and scalable method of integrating SDG research and research-based education within undergraduate curricula.

Social implications - The paper has the potential to deliver SDG-related impact in target communities by linking research-based teaching and learning with community outreach.

Originality/value - The alignment of VIP with the SDG research area is novel, with no other FE institutions currently using this approach to embed SDG research-based teaching within their curricula. Furthermore, the interdisciplinary feature of the VIP programme, which is critical for SDG research, is a Strathclyde enhancement of the original model.
\end{abstract}

Keywords Interdisciplinary, Sustainable Development Goals,

Research-Based Education for Sustainable Development, Vertically Integrated Projects,

Novel teaching pedagogy, Research-based teaching and learning

Paper type Research paper

(C) Scott Munro Strachan, Stephen Marshall, Paul Murray, Edward J. Coyle and Julia SonnenbergKlein. Published by Emerald Publishing Limited. This article is published under the Creative Commons Attribution (CC BY 4.0) licence. Anyone may reproduce, distribute, translate and create derivative works of this article (for both commercial and non-commercial purposes), subject to full attribution to the original publication and authors. The full terms of this licence may be seen at http://creativecommons.org/licences/by/4.0/legalcode

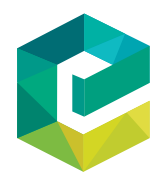

Received 31 October 2018 Revised 23 April 2019 Accepted 16 May 2019

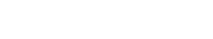


IJSHE

20,8

1314

\section{Introduction - what are Vertically Integrated Projects?}

Vertically Integrated Projects (VIP) is a new, innovative style of research-based education that the University of Strathclyde has adopted from Georgia Institute of Technology (GTech), where it was originally conceived. In partnership with academics from GTech, Strathclyde has enhanced this teaching model by aligning it with the United Nations' SDG Agenda 2030, and including interdisciplinary collaboration through "horizontal integration" across all four of its faculties.

What is particularly novel about the VIP approach is that research teams consist of undergraduate students ranging from all year groups; encouraging students to work continuously on the same project (gaining academic credit) throughout their University career. This "vertically integrated" approach ensures a constant throughput of students is maintained, where "new generations" of students joining the team can build on the successes of, and learn lessons from, students who have gone before them. Overtime, these VIP teams can reach a critical mass and level of continuity that allows the formation of longterm research groups, consisting primarily of undergraduate students. This allows teams to address relatively bold and ambitious research challenges.

VIP was designed to enable undergraduate students to earn academic credits while working on real-world research challenges, in conjunction with research staff and academics. This offers a richer, more experiential and self-motivated approach to learning for students. Simultaneously, research staff and academics could leverage this largely untapped undergraduate research resource to support their ongoing research projects - and even explore new research opportunities.

Other institutions have implemented similar programmes for similar reasons. One of the most notable being University College London's (UCL) “Connected Curriculum”, which recognized the opportunity to align undergraduate teaching and learning with their institution's ongoing research portfolio. Engaging students in academic-led research opens up a new institutional dimension to undergraduates, and offers them an opportunity to engage directly with research staff and academics; developing and applying new skills to help deliver research impact as an integral part of their studies. The notion of embedding undergraduate students within a university's research community to develop their research skills is defined by UCL as "Research-Based Education" (RBE), and the "Connected Curriculum" (Fung, 2017) is their unique approach to enabling this. As is the case with UCL's Connected Curriculum, the VIP model presented in this paper also offers a mechanism for embedding RBE in undergraduate curricula; allowing students to gain academic credit while contributing to global research challenges that also develops the competencies required for their future careers.

Prior to the Connected Curriculum and VIP, the relationship between research and teaching was separated into three distinct classes by Griffiths (2004). These classes were described as "research-led" teaching, where students are taught about current research in the discipline; "research-oriented" teaching, where there is teaching of research and inquiry skills and methods, and "research-based" teaching, where students become research active, undertaking research and inquiry. Healey and Jenkins (2009) later made a further distinction between these approaches, with regards to the extent to which they treated students as passive audience members or active participants in research, and to what extent students were encouraged to become "knowledge producers" as opposed to "consumers" in tackling real-world problems. In most cases, research-based learning is considered to be the combination of inquiry-based learning and undergraduate teaching, where inquiry-based learning also encompasses project-work, field-work and case-studies. Fung describes it as reflecting "the kinds of active, critical and analytic enquiry undertaken by researchers" - 
involving competencies that be difficult to develop through the traditional classroom mode of teaching, often referred to as "subject-based learning". This is at the heart of the VIP model, which can be considered as a means of enabling RBE, with the potential to encompass all of these characteristics, but critically involved collaborative working and learning (Bruffee, 1993) between students and research staff on research projects with pathways to impact.

More recently, the University of Strathclyde, like many other higher education institutions (HEIs), has been actively searching for innovative ways of embedding education for sustainable development (ESD) in its curricula, to actively engage students in the UN's SDGs.

This paper discusses how aligning VIP with the SDG framework presents a powerful means of combining both research-based education (RBE) and education for sustainable development (ESD), as a means of effectively embedding research-based education for sustainable development (RBESD) in undergraduate curricula.

This paper will offer a historical view of how Strathclyde's VIP programme has evolved; and how enhancing the original VIP model through the introduction of "horizontal integration" has opened up opportunities for interdisciplinary collaboration in teaching and research. Given the multi-faceted and interconnected nature of the SDGs, the need for this horizontal integration is required to properly embed a programme of RBESD at an institutional level. The paper also offers the reader an appreciation of the scale of intra and inter-institutional participation, and the future vision for this scale-up. A reflective discussion of the "Strathclyde experience" in setting up and operating its VIP for Sustainable Development (VIP4SD) programme is included, which also includes recommendations for consideration by other institutions interested in developing their own programme as a means of embedding RBESD in their curricula. Through the use of a Strathclyde case study, the paper will present a VIP4SD exemplar project at Strathclyde to provide some context to the practicalities associated with its operation and the benefits it can offer students and researchers. This reflection will highlight and discuss some of the challenges already faced in the initial set-up of the programme and those envisaged as it scales up.

\section{Development and evolution of Vertically Integrated Projects - a historical perspective}

The precursor to VIP was a teaching programme initially implemented at Purdue University in 1995 - The Engineering Projects in Community Service (EPICS) programme (Coyle et al., 1996). This programme engaged students on long-term, practical engineering projects focussing on local community needs.

To address the need for resource continuity which could make these projects long-lasting and sustainable, a "vertically integrated" approach (involving students from different year groups) was introduced to form long-term project teams. The success of this programme was acknowledged by the National Engineering Academy in its award of the Gordon Prize for Innovation in Engineering and Technology Education (Coyle et al., 2005). As practical and impactful as these projects were, they remained focussed on community engagement and outreach, with no explicit research dimension. This led academic staff, supervising project teams, to limit their time on these projects, and ultimately led to staff disengagement from the programme (Alber et al., 2017; Coyle et al., 2006; Melkers, 2012). This instigated the EPICS programme's evolution into the more research intensive VIP programme at GTech. Now staff were offered the incentive to operate VIP projects which could support ongoing research, or even explore new avenues of research. The renaming and refocusing of the VIP 
IJSHE 20,8

model adopted at GTech ensured the same emphasis was placed on the research dimension as much as the social or community engagement dimension of the project. Therefore, by ensuring projects involved some practical "real-world" application and novel contribution to the broader research field, served to retain all of the characteristic of community engagement associated with EPICS, but with an added research dimension. At GTech this approach was more successful in retaining staff engagement and facilitated the scaling up of the programme. From a teaching and learning perspective, staff also acknowledged that this approach developed key research competences in undergraduates, which are better learned through a more immersive, experiential approach to teaching and learning, made possible through working on real-world problems than through more conventionally taught classroom-based modules.

It is also worth noting that there appears to be an increasing occurrence of students who have progressed through VIP during their university studies, applying for $\mathrm{PhD}$ positions (potentially continuing their VIP research), though data supporting this remains to be collected. The benefits work both ways here, with students feeling more confident and selfassured in their decision to pursue a research qualification, and staff benefiting from the recruitment of students with already well-honed research skills. As such, VIP presents something of a ( $\mathrm{PhD}$ pipeline), and in so doing can extend the level of vertical integration into post-graduate education.

Currently 35 institutions worldwide have formed the VIP International Consortium partnership (Georgia Institute of Technology, 2015), which meets annually to share best practice and hold strategic discussions on expansion and opportunities for collaboration. There are over 300 VIP projects running worldwide engaging approximately 5,000 students in research-based, credit-bearing academic studies. The GTech VIP programme, which is the largest within the consortium, and as of academic year 2018-2019, comprises in the order of 70 project teams, involving approximately 1100 undergraduate students from 30 degree programmes from across campus; working on projects ranging from humanitarian-centred design to jetpacks for Mars.

\section{Adoption and operational challenges of Vertically Integrated Project - the Strathclyde experience}

The VIP teaching model was adopted at the University of Strathclyde in 2012, with the support of its creator, Professor Ed Coyle, and his colleagues at GTech in Atlanta. With the support of Department Heads, VIP was promoted as an opportunity for staff at Strathclyde to gain additional research resource and engage in a new way of teaching, offering students a different kind of learning experience. This resulted in the formation of nine VIP teams.

The main challenges exist around institutional promotion and acceptance, academic regulations, changes required to existing curriculum, assignment of academic credits, degree accreditation requirements, staff engagement and resource, student recruitment, assessment and supervision. While these challenges, or the extent to which they exist, may differ between institutions, the following represents a reflective account of those encountered at the University of Strathclyde, with some recommendations based on the "Strathclyde experience".

\section{Institutional promotion and acceptance}

As is the case with any new initiative, it is important to present a value proposition to those responsible for sanctioning change and innovation. As a means of delivering and embedding RBE in undergraduate curricula, VIP like any other RBE mechanism requires a change in the institutional perspective towards undergraduate teaching and institutional 
research. Rather than viewing these streams as independent, RBE actively promotes the nexus between student education and research, and the opportunities this opens up for connection and partnership across the institution.

The value proposition for introducing a VIP programme will generally centre on the introduction of innovative teaching, RBE and the "win-win" that is presented with respect to student experience and research support. Convincing senior academics and officers may be best achieved by proposing and implementing a plan for a proof-of-concept VIP pilot; initially involving a limited set of engaged academics. Furthermore, if it can be demonstrated that this programme resonates with aspects of your institution's strategic plan, this will also strengthen the case for its uptake.

A criticism sometimes levied at VIP, is its lack of scalability, with regards to its ability to accommodate all students from a given year, leading to staff-to-student ratios that make it costly and difficult to resource. However, the experience at GTech suggests that the potential for large team sizes creates staff-to-student ratios that make the VIP model entirely scalable in terms of students served; stressing that with an average team size of 16 at Georgia Tech, once fully scaled, every student on a campus could conceivably participate in VIP (Sonnenberg-Klien et al., 2018). Furthermore, alignment with existing classes (discussed later) has the potential to minimize the need for additional resource.

\section{Academic regulations}

Changes to academic regulations required to accommodate the vertically integrated degree pathway required for VIP across an institution, may or may not be required, or indeed possible, depending on the appetite that exists for this within the university, and the availability of any alternative means of developing such a pathway. Fundamentally, achieving "rules change" is unlikely to be a straightforward task. There are legitimate reasons for the immutability of the regulations, as these are designed to protect the academic integrity of all degree curricula university-wide. As such, a more pragmatic approach to developing VIP degree pathways is to align it with the existing degree curricula within specific departments, under the existing regulatory framework and with as minimal disruption to the curricula and department as possible. Achieving this requires collaboration between VIP programme coordinators, department heads and course directors, and examples of how this may be achieved are discussed next.

\section{Changes to and/or alignment with existing curriculum}

Perhaps the most universal approach to establishing a vertically integrated pathway through an existing degree curriculum, should an institution's regulations permit, involves offering VIP as an elective in consecutive years. However, academic regulations can often prohibit this; for example, elective credits may be limited to particular years of study which is obviously problematic when searching for a vertically integrated pathway through a degree via this route.

An alternative approach can be to find "container classes". These would be existing class modules that involve the same level of student effort (and credit) as required by a VIP project in one academic year, and which have learning outcomes that VIP can encompass. For example, an existing project-based or case study-based module, running across an academic year, could be used to "host" a VIP project for that year of its pathway. Often such modules and their registrars are actively seeking subject matter and topics, and so the opportunity to form a student group around a VIP topic is often welcome.

In earlier years of study, the elective and/or container class approach can often be the most effective, and less invasive, method of VIP pathway development. However, in later
Development in

undergraduate curricula

1317 
IJSHE 20,8

years (i.e. 4 and 5), opportunities to use electives and container classes to host VIP can become extremely limited, or even non-existent. Therefore, to achieve vertical integration and project continuity in later years, it can be necessary to use individual or group (capstone) projects to enable students to continue with their VIP research. In such cases, the dynamic of the VIP can change from the students' perspective. Students continuing their VIP research through an individual project in fourth year have the potential to feel disconnected from the rest of the group, but this can be easily remedied by keeping the student involved in VIP team meetings, mentoring and planning; all of which can be accounted for in the student's individual project conduct grading. It is important however, to ensure that the integrity of the individual student project is protected and not at risk of being compromised by lack of progress from the wider VIP project team. Therefore, the scope of the individual student project can be complementary to the broader VIP research. For example, this could involve focussing on a particular function of a suite of software being developed by a VIP team. However, it is worth stressing that while this project can be complementary, it must not be critically dependent on outputs from the wider VIP team.

In practice, a combination of electives, container classes, individual and group student projects offers the most pragmatic means of forging a VIP pathway through a given degree course.

\section{Assignment of academic credits}

Credit structures for degrees can vary between institutions, but this should not necessarily cause any obstruction to the establishment of a VIP programme. Ideally, the number of credits would remain consistent across all degrees and year groups involved with a VIP to ensure the same level of consistency in the commitment of time and effort across the team. However, when attempting to establish VIP within "ready-made" degree pathways, essentially through a mix of electives and container classes, this may not always be possible. In such cases, there is the prospect of different credits being awarded to different VIP students in different years of study and/or different degrees. Therefore, this can result in multi-disciplinary, multi-year groups forming where students attain different levels of credit, but are required to work collaboratively. Obviously, the number of credits awarded is reflective of the amount of student effort involved with a module. Therefore, there is the potential for different levels of student engagement, resulting from this disparity in the credits awarded, to adversely affect the progress of the project and group dynamic. In such cases it is necessary to make clear the expectations set on individual students and ensure that the assignment of group roles respect and reflect the distribution of credits across the group.

It is recommended that VIP projects operate over the full academic year - for example, over both semesters of a two-semester system of study. This means that some students may be awarded the credits typically associated with full-year study, but may be required to work with other students gaining credits that amount to less than this, in some cases equating to only one semester of study. Where feasible, the timeframe for activity should remain consistent (the full year), but students gaining less credit should spread their effort out across the full year, rather than concentrating this into one semester. This encourages greater collaboration and continuity in the project, but it is important that students guard against becoming too involved to the detriment of their other classes. Students are therefore required to maintain logbooks or journals describing their ongoing project contribution. This represents a useful record of the progress of individual students, which can also be useful when distinguishing between individual levels of contribution for final assessment. 
Supervisors can routinely check these to ensure that each student's contribution is in line with expectations based on the number of credits they are being awarded.

\section{Degree accreditation}

While accreditation bodies ensure the applicable standards are met by degrees in specific disciplines, introducing new classes involving "less conventional" teaching methods, that may not have been included in the most recent review, can sometimes be challenging. Aligning the VIP programme with already accredited "container modules", etc. as discussed previously, avoids the need to wait for accreditation reviews before implementation; providing the learning outcomes, competencies, etc. of the already accredited container class can be encompassed by the VIP project "inhabiting" it. However, it is important that institutions work with accreditation bodies to ensure flexibility exists for innovation in teaching and learning.

\section{Staff recruitment, engagement and resource}

Ultimately, any programme of teaching or research will require staff time and effort to service it. It is therefore important that the incentives for staff to engage are made clear, and ensure that appropriate support is available to staff - particularly in the early stages and years of establishing and running a VIP project. Available resource will often vary between departments, however, by strategic alignment of VIP with "container classes" there is potential to incorporate VIP with limited additional staff resource requirement. It is essential however, that participating staff be prepared to engage with these student projects on a longer-term basis than they may have been used to previously, and so a genuine interest in, and commitment to supporting the VIP programme must exist.

Experiences at GTech suggest that as a VIP programme grows, increasing returns to scale are evident, which can serve to encourage broader participation. Furthermore, as the programme builds, academics and researchers become more convinced of the potential benefits that VIP offers their research in terms of additional resource and potential pullthrough of $\mathrm{PhD}$ students, which facilitates further growth. The main challenges exist in the initial stages of programme implementation. Initially, identifying and committing staff to starting up and running a VIP without any institutional track record or existing community of practice within the university can be challenging, but seminars and existing network connections can prove useful in identifying and targeting interested staff, and getting them enthused and enaged. VIP successes reported at other universities where programmes have been in operation for a number of years, and visits from academics from these institutions to deliver first-hand their experiences, can serve to reassure staff of the value of VIP and its viability.

\section{Student recruitment}

Promotion events are arranged at the beginning of term, where students are invited to attend and find out more about VIP; what it can offer them and how they can apply onlinefrom which shortlists are then created for interview.

VIP at Strathclyde is selective, but not academically elitist. Student selection is not based entirely on academic record alone; it also considers a student's motivation, enthusiasm and experience. Consequently, while VIP is offered to all students in a department where it is available, students are not automatically guaranteed of a position on a team should they select this option. This selection process is to some extent driven by the limitations on resource and team sizes associated with some teams. However, this selection process also offers students useful application and interview experience; readying them for the graduate
Development in

undergraduate curricula

1319 
IJSHE 20,8

recruitment phase awaiting them on completion of their time at University. Furthermore, successful selection onto a VIP team instils a sense of achievement and appreciation for the opportunity that tends to serve the student and project well.

Another event used to promote VIP to students is the annual conference, where students interested in finding out more about VIP can see students showcase their work through Pecha Kucha presentations, Dragons' Den/Shark Tank (renamed as VIPer Pit) events and poster sessions. This gives students the opportunity to hear unvarnished accounts of the VIP experience directly from their peers, and also offers existing teams the opportunity to become proactive in the recruitment of new members for the coming year.

\section{Project assessment and supervision}

Critical to the ongoing operation and longevity of a VIP is the additional supervisory support available from research staff and $\mathrm{PhD}$ students, who play a vital role here, and who can also feature in succession planning as prospective VIP leads.

In addition, and not to be underestimated as a supervisory resource, are the students themselves. The set-up of VIP projects gives students the time and latitude required to indulge in deeper learning, which is obviously beneficial to both the student and wider project. Furthermore, allowing students to remain engaged with a project over consecutive years, and having them work with "junior" students, sets up a knowledge hierarchy which can be exploited to encourage peer-to-peer learning and mentoring. This means that over time the supervision role would be expected to become more passive as the project evolves to become more student-centred in its operation.

The assessment of VIP students is generally devolved to departments. Therefore, VIP teams with students from different disciplines will have supervising academics from these disciplines who will be responsible for deciding on the most suitable method of assessment. In general, a group report and presentation and conduct grade offers an effective method of assessment.

\section{Embedding RBESD in curricula - aligning VIP with the SDGs}

UNESCO has been promoting Education for Sustainable Development (ESD) since 1992; leading the UN Decade for ESD from 2005 to 2014. ESD is now at the forefront of the Global Action Program (GAP). The UNESCO report, "Education for Sustainable Development Goals: Learning Objectives" (UNESCO, 2017) was published as a guide for education professionals on the use of ESD in learning for the SDGs. The report is driven by the acknowledgment of education as both "a goal in itself and a means for attaining all the other SDGs. It is not only an integral part of sustainable development, but also a key enabler for it".

In 2016, Strathclyde demonstrated its commitment to ESD by realigning its VIP programme with the UN SDG framework, and renaming its programme "VIP for Sustainable Development" (VIP4SD). In doing so, Strathclyde challenged its students to work together as one to address these Global Goals, by applying their "useful learning" to the interconnected, real-world and multi-faceted problems underpinning each of these goals. The SDGs therefore present a framework of "wicked problems" (Rittel and Webber, 1973) that form the basis for embedding RBESD in undergraduate curricula.

Initially, existing VIPs were mapped onto SDGs that served as their primary focus, and on which each project's impact and focus could be justified in terms of the corresponding SDG targets. Table 1 shows a summary of the existing VIP4SD projects, in terms of staff/ student ratios and disciplines associated with each team. A more detailed explanation of each of these projects can be found at (Strathclyde University, 2016). 


\begin{tabular}{|c|c|c|c|c|c|}
\hline Team name & Research objective & $\begin{array}{l}\text { Students } \\
\text { staff/student } \\
\text { ratio }\end{array}$ & $\begin{array}{l}\text { Primary } \\
\text { SDG }\end{array}$ & Student majors & undergraduate \\
\hline \multirow[t]{2}{*}{ Drug discovery } & \multirow[t]{2}{*}{$\begin{array}{l}\text { To combine microbiology and } \\
\text { image processing to develop new } \\
\text { tools for drug discovery and better } \\
\text { ways to produce antibiotics }\end{array}$} & \multirow[t]{2}{*}{$3 / 16$} & \multirow[t]{2}{*}{ SDG3 } & \multirow{3}{*}{$\begin{array}{l}\text { Microbology } \\
\text { Electronic and Electrical } \\
\text { Engineering } \\
\text { Computer and } \\
\text { Electronics Science } \\
\text { Electrical \& Mechanical } \\
\text { Engineering } \\
\text { Business }\end{array}$} & 1321 \\
\hline & & & & & \\
\hline Enterprise VIP & $\begin{array}{l}\text { To embed business students as } \\
\text { commercialization consultants in } \\
\text { other research activities through } \\
\text { VIP }\end{array}$ & $5 / 70$ & SDG8 & & \\
\hline ROVER & $\begin{array}{l}\text { To embed business students in a } \\
\text { real-world, team-based engineering } \\
\text { research project to design, build } \\
\text { and test robots for the } \\
\text { improvement of human causes }\end{array}$ & $2 / 15$ & SDG9 & $\begin{array}{l}\text { Design Manufacture } \\
\text { and Engineering } \\
\text { Management } \\
\text { Electronic and Electrical } \\
\text { Engineering } \\
\text { Mechanical and } \\
\text { Aerospace Engineering } \\
\text { Physics }\end{array}$ & \\
\hline STEM education & $\begin{array}{l}\text { To develop STEM reasoning skills } \\
\text { in areas of deprivation (SIMD - 40) } \\
\text { through public engagement in } \\
\text { schools and the local community }\end{array}$ & $2 / 14$ & SDG4 & Education, Engineering & \\
\hline $\begin{array}{l}\text { Sustainable } \\
\text { energy for } \\
\text { development }\end{array}$ & $\begin{array}{l}\text { To challenge students to tackle } \\
\text { sustainable development goal } \\
\text { number } 7 \text { - universal energy } \\
\text { access. Links with outreach } \\
\text { programs delivering VIP research } \\
\text { impact on the ground by delivering } \\
\text { new energy solutions in the } \\
\text { Gambia and India }\end{array}$ & $3 / 16$ & SDG7 & $\begin{array}{l}\text { Design Manufacture } \\
\text { and Engineering } \\
\text { Management } \\
\text { Electronic and Electrical } \\
\text { Engineering } \\
\text { Electrical and } \\
\text { Mechanical Engineering } \\
\text { Business }\end{array}$ & \\
\hline TextLab & $\begin{array}{l}\text { To conduct research and develop } \\
\text { software tools for textual analysis } \\
\text { that provide new and interesting } \\
\text { analyses of Shakespeare's works } \\
\text { and enable us to find things that } \\
\text { are not always visible to the naked } \\
\text { eye }\end{array}$ & $4 / 28$ & SDG4 & $\begin{array}{l}\text { English } \\
\text { Computer and } \\
\text { Information Science }\end{array}$ & \\
\hline $\begin{array}{l}\text { Water and } \\
\text { sanitation } \\
\text { (WASH) }\end{array}$ & $\begin{array}{l}\text { To focus research across the } \\
\text { University that can help with the } \\
\text { United Nations statistics on Water, } \\
\text { Sanitation and Hygiene (WASH) } \\
\text { The VIP team are actively } \\
\text { involved with a wide selection of } \\
\text { real-world problems that affect } \\
\text { Malawi's Integrated Water } \\
\text { Resource Management (IWRM) }\end{array}$ & $8 / 57$ & SDG6 & $\begin{array}{l}\text { Civil Engineering } \\
\text { Environmental } \\
\text { Engineering } \\
\text { Hydrogeology } \\
\text { Electronic and Electrical } \\
\text { Engineering } \\
\text { Mechanical Engineering } \\
\text { Business } \\
\text { Accounting } \\
\text { Law }\end{array}$ & $\begin{array}{r}\text { Table I. } \\
\text { Summary of } \\
\text { Strathclyde VIP for } \\
\text { sustainable } \\
\text { development } \\
\text { (VIP4SD) programme }\end{array}$ \\
\hline
\end{tabular}


IJSHE 20,8
One year following this realignment, another six VIP4SD teams have been proposed and will be introduced in academic year 2019-2020. Many of the existing teams have grown to become "umbrella" projects, hosting a number of sub-projects. For example, the "Sustainable Energy for Development - SEfD" VIP4SD project currently hosts four subprojects, each focussing on different research challenges associated with increasing global energy access (i.e. SDG 7), while the "STEM Education" VIP4SD project has sub-projects focussing on developing innovative teaching methods to promote and improve STEM education and attainment in local primary schools located in lower participation neighbourhoods of Glasgow, and also within an international development context, working with teacher training bodies in Malawi and The Gambia (i.e. SDG 4).

A 2018 NUS survey considering student perceptions of sustainability in higher education (NUS, 2018) clearly shows how undergraduate students are a force that is ready and waiting to be mobilized, to make meaningful and tangible contributions now in shaping a sustainable future for themselves and all of us. The UN has acknowledged this critical role that young people will play in achieving the SDGs having launched the "Youth 2030 initiative" to, in the words of the Secretary-General's Envoy on Youth, "leverage the untapped potential of young people" (UN, 2018).

In the report "Getting Started with SDGs in Universities"- Monash University say that "young people are creative, energetic, idealistic and optimistic about the future, and so want to make global, challenging and meaningful contributions to SDGs", and that "Universities can harness their unique access to large concentrations of young people for this purpose" (Kestin, 2017). However, students have more to offer the challenge of Sustainable Development than their enthusiasm; they have the skills and energy to deliver impact now, providing this can be properly channeled. In 2025 the global student population in Further and Higher Education will reach more than 260 million (Goddard, 2011), and so the question for HEIs is "how can we best partner with our students now and in the future to leverage this potential to its full in the pursuit of the SDGs?".

The VIP4SD pedagogy engenders a sense of collective responsibility among students to support each other and positively impact the target communities they serve. This can act as a potent incentive for students to develop a deeper understanding of difficult subject matter and confront threshold concepts that would otherwise act as bottleneck to future learning (Meyer and Land, 2005).

High impact activities engaging students in practical community-based projects (be they set in local areas in and around students' home cities, or in remote locations in Sub-Saharan Africa) can present a genuine sense of purpose and source of inspiration for students, to which they can apply their newfound knowledge (Conger et al., 2010). The effect can be to motivate students to actively participate in a deeper level of learning and understanding (Hounsell, 1997); motivated not only by their own personal academic gain, but also by their potential to positively impact their target communities, e.g. by designing an off-grid system for a remote rural community currently with no electricity access.

In explaining why high-impact learning activities are so effective (Kuh, 2008) suggests that it may be due to the need for students to "devote considerable time and effort to purposeful tasks; requiring daily decisions that deepen students' investment in the activity as well as their commitment to their academic program and the college". The SEfD VIP4SD project (like most others) frames its learning objectives as a set of "purposeful tasks", aimed at making some form of positive societal impact, and which arguably provide a greater incentive and motivation for students to engage with the learning process than that offered by more traditional teacher-centred pedagogies culminating in some form of assessment as its end-goal. 
VIP4SD therefore presents an opportunity for students to benefit from a transformative learning experience, where students can be empowered to critically reflect on the VIP4SD experience, with the potential to change their worldview (Moore, 2005). This paper argues that RBESD offers an opportunity for collaborative working and high-impact learning to take place between staff and students, and VIP4SD presents a mechanism for embedding this within undergraduate curricula.

\section{Horizontal integration of Vertically Integrated Project}

While vertical integration enables the construction of large research teams capable of addressing long-term research goals, Strathclyde introduced a horizontally integrated dimension to the VIP model to foster cross-faculty collaboration. Both aspects present challenges in the set-up, coordination and administration of the VIP4SD programme as outlined previously, but offer many benefits.

Horizontal integration of project teams opens the opportunity for students to interact with, and teach and learn from those working out with their own discipline. It is in the interests of the project that students not only become experts in a focussed area of research relevant to the project goals, within their own field of study, but that they learn new skills and gain new knowledge in other fields outside of this. For example, engineering students may be required to explain the basic concepts of power and energy to business students, while business students may be required to explain the basic principles of conducting a market assessment or cost/benefit analysis in return.

Communicating basic and complex concepts to "non-experts" and communicating with others using a "common vocabulary" are skills our graduates often only develop in the workplace - post-university. The interdisciplinary nature of the VIP4SD programme offers students the opportunity to develop "softer", non-technical, but transferrable communication, project management and team-working skills in an authentic real-world, problem-solving context. These skills can be difficult to teach with any degree of authenticity in the conventional classroom setting, but increasingly degree accreditation bodies are stipulating the need for HEIs to integrate this type of skills development within curriculum teaching, principally in response to employers' needs and demands. This is also emphasized by The UK Commission for Employment and Skills (UK Commission for Employment and Skills, 2009) which urges universities to invest more in developing both curricula and teaching staff to improve students' work-related attributes and their employability - and in particular "build an institutional culture that promotes employability" and "make the learning environment resemble the workplace". This paper argues that VIP4SD fosters such an environment.

The cross-faculty dimension to VIP4SD at Strathclyde has also provided a platform for collaboration between research staff. Project requirements drive the recruitment of students with particular disciplinary skill-sets from specific degree courses; often connecting supervising research staff across different faculties and departments in the process. This has the potential to lead to broader research collaboration. The horizontal integration of VIP also offers the opportunity to completely institutionalize the programme, making this an option open to all undergraduate students in all faculties.

As discussed, Strathclyde has been largely responsible for the horizontal integration of project teams to embrace the opportunities that exist for interdisciplinary undergraduate research, which is required to competently and comprehensively address the multi-faceted challenges associated with the SDGs, as previously discussed.
Development in

undergraduate curricula

1323 
IJSHE

20,8

1324
Case study - "Sustainable Energy for Development" Vertically Integrated Project

A case study of The Sustainable Energy for Development (SEfD) VIP is presented here as an exemplar of the VIP4SD programme. This project focuses on SDG 7 - Ensure access to affordable, reliable, sustainable and modern energy for all.

The SEfD VIP4SD project emerged from a staff/student outreach programme which has successfully installed solar PV installations in eleven primary schools across rural Gambia (Strathclyde University Gambia Solar Project, 2010) since 2006. There is now even interteam collaboration between the Education and SEfD projects, where research is being conducted into the impact that school electrification can have on grades and attainment in rural villages.

The SEfD project challenges students to design, build and install energy solutions and supporting technologies that can provide affordable, renewable off-grid electricity capable of transforming the lives of some of the world's most impoverished and remote communities. This project engages engineering, business and social science students in SDG 7 related research throughout the academic year. Engineering students are responsible for the design of energy technology solutions, and business students for developing business models for income generation that make these solutions technically and economically sustainable; while social science students can assist in the development of appropriate solutions that are sensitive to the social and cultural sensibilities of target communities. Social science and business students can also work together to measure the social-economic impact of these solutions.

The SEfD project has retained the outreach arm, which delivers energy access solutions in rural Gambia and South East India. This offers a real-world context and platform where students can apply their knowledge and understanding beyond traditional teaching boundaries and environments (Moore, 2005). Here, students can deploy and test their research outputs in the field, within these remote rural communities, and measure their impact. One such example was the installation of remote monitoring (RM) technology, developed by engineering students during term time as the focus of their VIP4SD project. This prototype was installed in two Gambian schools where previous cohorts had installed solar PV systems for lighting and phone charging. The RM system was designed specifically to bridge the sustainability issues associated with the lack of technical skills and capacity that exists in off-grid communities. This RM technology was designed to give the team at Strathclyde visibility of how the schools systems were being utilized and performing; providing early warning of any faults or problems arising with these systems. Therefore, students were involved in the complete design cycle, where they identified the "need" for a technical solution (i.e. remote monitoring) to improve the sustainability of the system. In addition, the project team learned from the issues that then occurred during and after deployment, which were then factored into future design iterations.

To date, the SEfD VIP and its community engagement/outreach arm (i.e. staff-student led "Gambia and Tamil Nadu Solar Project") has involved approximately 60 students in the successful installation of fourteen off-grid PV systems in remote rural schools, colleges and health clinics across The Gambia and Vellore. In 2016, a Strathclyde SEfD VIP student won "best student mobility experience" at the international QS (University World Rankings) Conference, for his contribution to "The Gambia Solar Project" (The Engineer, 2016). The awards panel also acknowledged the role of the University's VIP4SD programme in the "organization, management and support of international educational experiences."

In addition to supporting these outreach programmes, the SEfD project operates alongside and supports externally funded research programmes within the Department of 
Electronic and Electrical Engineering at Strathclyde, which focus on Energy for Development research. This requires routine interaction between undergraduate and postgraduate students; where VIP4SD project output can feed directly into the research of $\mathrm{PhD}$ students and post-doctoral research staff.

The SEfD VIP (like most others) frames its learning objectives as a set of "purposeful tasks", aimed at making some form of positive societal impact, and which arguably provide a greater incentive and motivation for students to engage with the learning process than that offered by more traditional subject-based, teacher-centric pedagogies culminating in

Development in

undergraduate curricula

1325 some form of assessment as its end-goal.

SDG No.7 (like others) effectively presents a "wicked problem" that first requires students to understand its societal context and broader research landscape before identifying where they can make a positive and meaningful contribution as a group. Students are invited to define ambitious long-term goals, but also have achievable and tangible short-term outcomes. From this, and in the spirit of co-creation, students can work with academics to define their own set of project objectives. The SEfD VIP4SD project has five sub-teams each focussing on complementary areas of energy access research. The main objectives of each sub-project are described as follows:

(1) develop microgrid design tools to optimize the layout and operation of these systems deployed in rural areas of sub-Saharan Africa;

(2) develop efficient and low energy electrical cooking appliances that can be connected to solar home systems deployed in developing countries with low electricity access rates;

(3) design sustainable energy hubs servicing the energy needs of commercial sectors in rural settings;

(4) develop the supervisory control and data acquisition system required for the operation of a village microgrid; and

(5) develop a business model for a social enterprise focussing on installing off-grid solar PV systems in Malawian schools with no access to electricity.

These high-level objectives are then broken down into a series of planned R\&D activities, delegated across the VIP4SD team by supervisors in consultation with the student team. Involving the students in the problem definition and its articulation in their submitted "statement of intent", serves to instil a sense of ownership among the students - this is their project, they defined it and understand the motivation for it. For some students this can present an extremely compelling case for learning and serves to "connect" students more with the learning process.

All VIP4SD projects participate in the Annual VIP for Sustainable Development Conference hosted at Strathclyde. This conference, true to the student-centred spirit of VIP4SD, is organized by the students for the students. Students form an event organizing committee that organizes all aspects of the conference, including marketing, registration, organization of abstract submissions, posters, even a Dragons' Den (aka VIPer Pit) event where teams are able to pitch for funding for their projects.

\section{Next steps - Institutional challenges in deploying Vertically Integrated Projects for Sustainable Development}

Having demonstrated the implementation and effectiveness of the VIP4SD as a means of embedding RBESD in undergraduate curricula at a limited (pilot) scale, there are now plans 
IJSHE 20,8

in place to scale up this effort and fully integrate the VIP4SD programme with existing degree curricula across all departments and faculties, and so effectively institutionalizing RBESD at Strathclyde.

Our aim over the next five years is to expand the existing VIP4SD portfolio of 9 teams and 200 students - to the order of 50 teams, involving over 800 students, bringing Strathclyde in line with GTech. The main challenge in achieving this "institutionalizing" effect is the need to identify pathways through existing degree curricula to accommodate the vertical and horizontal dimensions of these projects, as discussed previously. There is no doubt that this will be challenging, and will require changes to conventional teaching methods and well-established curricula and timetables. However, it is envisaged that this will be justified by the positive impact the programme is anticipated to have on the student experience, the institutions' teaching and research profile, the communities targeted by VIP4SD outreach arms and the broader teaching and learning, and research communities.

Work is currently underway to conduct a comprehensive qualitative and quantitative analysis of the impact that involvement in the VIP4SD programme has on participating students when compared with their non-participating counterparts and peers, as well as its institutional benefit. This will attempt to evaluate how well the core ESD and RBE competencies have been developed in students, as well as capturing levels of student (and staff) interaction and satisfaction associated with programme engagement.

\section{Conclusions}

The paper presents the experiences of the University of Strathclyde in the roll-out of its VIP for Sustainable Development (VIP4SD) programme as a means of embedding SDG related, research-based teaching and learning in the undergraduate curricula, across all four faculties. The VIP teaching model presents an ideal vehicle for the implementation of research-based education and offers the continuity and interdisciplinarity of research resource required to tackle the SDGs.

This programme therefore offers students the opportunity for high-impact learning, where projects are linked with outreach/community engagement, and so allowing students to appreciate the impact their discipline can have in local and global social contexts. This programme offers students the type of challenge that motivates them to actively participate in a deeper level of learning and understanding; motivated not only by their own personal academic gain but by their potential to make a difference to the lives of more vulnerable communities.

VIP4SD perhaps has the potential to operate on a grander, global scale, with a vision that seeks to mobilize, scale-up and coordinate student research and outreach effort on an institutional level, and potentially at national and even international levels through crossinstitutional collaboration and partnership.

The paper discusses the anticipated impact of the VIP4SD programme through the use of a case study with respect to improving the student experience, supporting academics in ongoing research and delivering impact.

Ultimately the VIP4SD programme, presents a means of embedding RBESD in undergraduate curricula, which can inspire, educate, equip and mobilize undergraduate students to remain engaged with the SDG agenda during and beyond their University careers to meet the challenges of sustainable development moving forward. 


\section{References}

Alber, R.T., et al. (2017),. "Vertically integrated projects programs at international institutions: multidisciplinary projects with homes in any discipline", ASEE Annual Conference and Exposition, Columbus, $\mathrm{OH}$.

Bruffee, K. (1993), "Collaborative learning: Higher education, interdependence and the authority of knowledge", Journal of the National Collegiate Honors Council, Vol. 1, pp. 91-99.

Conger, A.J., Gilchrist, B., Holloway, J.P., Huang-Saad, A., Sick, V. and Zurbuchen, T.H. (2010), "'Experiential learning programs for the future of engineering education", Transforming Engineering Education: Creating Interdisciplinary Skills for Complex Global Environments, IEEE, Dublin, pp. 1-14.

Coyle, E.J., Allebach, J. and Krueger, J. (2006), “The vertically integrated projects (VIP) program in ECE at purdue: fully integrating undergraduate education and graduate research", ASEE Anual Conference and Exposition, ASEE, Chicago.

Coyle, E.J., Deitz, H.G. and Jamieson, L.H. (1996), “"Long term community service projects in the purdue engineering curriculum”, ASEE Annual Conference Proceedings, ASEE, Washington, $D C$.

Coyle, E.J., Jamieson, L.H. and Oakes, W. (2005), "Integrating engineering education and community service: themes for the future of engineering education", Journal of Engineering Education, Vol. 95 No. 1, pp. 7-11.

Fung, D. (2017), A Connected Curriculum for Higher Education, UCLPress, London.

Georgia Institute of Technology (2015), "VIP consortium website", available at www.vip.gatech.edu/ vip-consortium (accessed 23 April 2019).

Goddard, B. (2011), Making a Difference: Australian International Education, University of New South Wales Press, Sydney.

Griffiths, R. (2004), "Knowledge production and the research-teaching nexus: the case of the built environment disciplines", Studies in Higher Education, Vol. 29 No. 6, pp. 709-726.

Healey, M. and Jenkins, A. (2009), Developing Undergraduate Research and Inquiry, The Higher Education Academy, New York, NY.

Hounsell, D. (1997), "Understanding teaching and teaching for understanding", in Ference, M., Hounsell, D. and Entwistle, N.J. (Eds), The Experience of Learning: Implications for Teaching and Studying in Higher Education, Scottish Academic Press, Edinburgh pp. 238-257.

Kestin, T. (2017), Getting Started with the SDGs in Universities, Sustainable Development Solutions Network - Australia/Pacific, Melbourne.

Kuh, G.D. (2008), High-Impact Educational Practices: What They Are, Who Has Access to Them, and Why They Matter, Association of American Colleges and Universities, Washington, DC.

Melkers, J. (2012), "The social web of engineering education: knowledge exchange in integrated project teams", ASEE Annual Conference and Exposition, ASEE, San Antonio, pp. 1-21.

Meyer, J. and Land, R. (2005), "Threshold concepts and troublesome knowledge (2): epistemological considerations and a conceptual framework for teaching and learning", Higher Education, Vol. 49 No. 3, pp. 373-388.

Moore, J. (2005), "Is higher education ready for transformative learning?: a question explored in the study of sustainability", Journal of Transformative Education, Vol. 3 No. 1, pp. 76-91.

NUS (2018), Student Perceptions of Sustainability in Higher Education - an International Survey, National Union of Students, London. 
IJSHE

20,8

1328

Rittel, H.W.J. and Webber, M.M. (1973), "Dilemmas in a general theory of planning”, Policy Sciences, Vol. 4 No. 2, pp. 155-169.

Sonnenberg-Klien, J., Abler, R.T. and Coyle, E.J. (2018), "Diversity and student persistence I the vertically integrated project (VIP) course sequence", Conference on Collaborative Network for Engineering and Computing Diversity.

Strathclyde University (2016), "Vertically integrated projects at strathclyde", available at www.strath. ac.uk/viprojects/ (accessed 23 April 2019).

Strathclyde University Gambia Solar Project (2010), "Gambia solar porject”, available at www.strath. ac.uk/engineering/electronicelectricalengineering/ourinternationalprogrammesprojects/gambia solarenergyproject/ (accessed 23 April 2019).

The Engineer (2016), "Strathclyde student winds award for Gambia energy project", available at www. theengineer.co.uk/stratchclyde-student-wins-award-for-gambia-energy-project/ (accessed 23 April 2019).

UK Commission for Employment and Skills (2009), “The employability challenge”, UK Commission for Employment and Skills.

UN (2018), "Youth2030 working with and for young people", available at www.un.org/ sustainabledevelopment/blog/2018/09/youth2030-launch/ (last accessed 23 April 2019).

UNESCO (2017), Education for Sustainable Development Goals: Learning Objectives, UNESCO, Paris.

Corresponding author

Scott Munro Strachan can be contacted at: scott.strachan@strath.ac.uk

For instructions on how to order reprints of this article, please visit our website: www.emeraldgrouppublishing.com/licensing/reprints.htm

Or contact us for further details: permissions@emeraldinsight.com 